REGULAR ARTICLE

\title{
EFFECT OF MANIPULATED ENVIRONMENTAL CONDITION ON THE DISTRIBUTION OF AERO-ALGAL COUNTS
}

\author{
JOGITA T. PANDKAR
}

Department of Botany, Fergusson College, Pune, India

\begin{abstract}
Reports on occurrence, distribution pattern, listing of aero-algal forms, seasonal calendar, allergenic aero-algal forms, effect of meteorological parameters on occurrence of aero-algal forms etc. has been reported by number of aero phycologists. But solution on reducing such aero-algal counts which can be a possible cause for allergenic reaction has not been suggested until known. Hence preliminary study with respect to effect of manipulated environmental condition on the distribution of aeroalgal counts has been done. Presence of cooling tower results into manipulation of the climatic factors, such as temperature and humidity percentage. The high humidity percentage act as an unfavorable condition for the surviving of aero-algal forms resulting into sporulation. This spores required some incubation period under favorable condition to undergo for its vegetative development. This knowledge can be used as a possible solution for the allergenic patients. Manipulation of climatic factors can be done both at intramural as well as extramural sites by using water coolers, A. C, introducing water falls etc. It can be considered as possible manageable solution for patient suffering from allergy due to aero-biological pollutants.
\end{abstract}

Keywords: Cooling tower, Humidity, Aero-algal counts, Allergy patients, Manipulated climatic factors.

\section{INTRODUCTION}

The air we breathe is full of bio-pollutants, one of which is aero-algae. Certain pioneer reference with respect to occurrence, distribution pattern, listing of aero-algal forms, seasonal calendar, allergenic aero-algal forms, effect of meteorological parameters on occurrence of aeroalgal forms etc. were reported earlier [1-9]. In India, the earlier passing references were reported [10-28].

Different meteorological factors have different effects on the distribution pattern and percentage occurrence of the aero-algal forms. But studies with respect to manipulated meteorological condition and its effect on the aero-algal counts has never been attempted. Hence the present criteria were considered for further studies.

\section{Material and methods}

Aero-algal sampling was carried out at two different industries having cooling tower within their factory premises, using rotarod air sampler [29]. Two parallel cellophane strips coated with petroleum jelly were mounted across the two bars of the rotarod sampler. Operational time of the sampler was $30 \mathrm{~min} / \mathrm{sample}$. One of the strip was mounted on a clean slide with glycerin jelly as mounting medium and other strip was dropped in a sterilized test tube containing B. G-11 culture medium. Cultures were allowed to grow under natural condition and were exposed to north side window under natural light condition. Slide mounting and culture inoculation procedure were carried out at the sampling sites to avoid contamination during transport.

\section{Site-I}

Peacock Industry-is a small scale industry manufacturing dye, situated on the Hingana side of M. I.D. C., Nagpur.

\section{Site-II}

Paper products Industry-is a small scale industry engaged in the manufacture of specially coated paper (required for costly wrappings as on toilet soaps or for pouch making as of pan-parag etc.) at M. I.D. C Wadi, Nagpur.

\section{Received 11 November 2017; Accepted 10 January 2018 \\ *Corresponding Author \\ Jogita T Pandkar \\ Department of Botany, Fergusson College, Pune, India \\ Email: jogita_pandkar@yahoo.co.in}

( This article is open access and licensed under the terms of the Creative Commons Attribution License (http://creativecommons.org/licenses/by/4.o/) which permits unrestricted, use, distribution and reproduction in any medium, or format for any purpose, even commercially provided the work is properly cited. Attribution - You must give appropriate credit, provide a link to the license, and indicate if changes were made. 
Table 1: Aero-algal forms recorded from peacock industry, M. I.D. C, Hingana

\begin{tabular}{lllll}
\hline S. No. & Particulars & Slide & Culture & Total \\
\hline 1 & Number of samples & 2 & 2 & 4 \\
2 & Total algal forms & 3 & 9 & 12 \\
3 & Cyanophyta & Nil & 7 & 7 \\
4 & Coccoid cyanophyta & Nil & 4 & 4 \\
5 & Filamentous cyanophyta & 3 & 3 & 3 \\
6 & Chlorophyta & Nil & 2 & 5 \\
7 & Bacillariophyta & 3 & Nil & Nil \\
8 & Trentipholia & Nil & Nil & 3 \\
9 & Plectonema notatum & Nil & 1 & 1 \\
10 & Merismopedia punctata & Nil & & \\
11 & Trebouxia & Nil & 1 & \\
12 & Lyngbya corticicola & Nil & 1 & 1 \\
13 & Chroococcus minutes & Nil & 1 & 1 \\
14 & Chroococcus minor & Nil & 1 & 1 \\
15 & Phormidium foveolarum & & 1 & 1 \\
16 & Chlorella & & 1 \\
\hline
\end{tabular}

Table 2: Aero-algal forms recorded from paper products, M. I.D. C, wadi

\begin{tabular}{|c|c|c|c|c|}
\hline S. No. & Particulars & slide & Culture & Total \\
\hline 1 & Number of Samples & 1 & 1 & 2 \\
\hline 2 & Algal Forms Recorded & 2 & 4 & 6 \\
\hline 3 & Cyanophyta & Nil & 4 & 4 \\
\hline 4 & Coccoid Cyanophyta & Nil & 2 & 2 \\
\hline 5 & Filamentous Cyanophyta & Nil & 2 & 2 \\
\hline 6 & Chlorophyta & 1 & Nil & 1 \\
\hline 7 & Bacillariophyta & 1 & Nil & 1 \\
\hline 8 & Trentipholia & 1 & Nil & 1 \\
\hline 9 & Chroococcus minor & Nil & 1 & 1 \\
\hline 10 & Merismopedia punctata & Nil & 1 & 1 \\
\hline 11 & Lyngbya lagerhaimii & Nil & 1 & 1 \\
\hline 12 & Microcoleus acutissimus & Nil & 1 & 1 \\
\hline
\end{tabular}

Graph-I: Comparative account of aero-algal forms observed

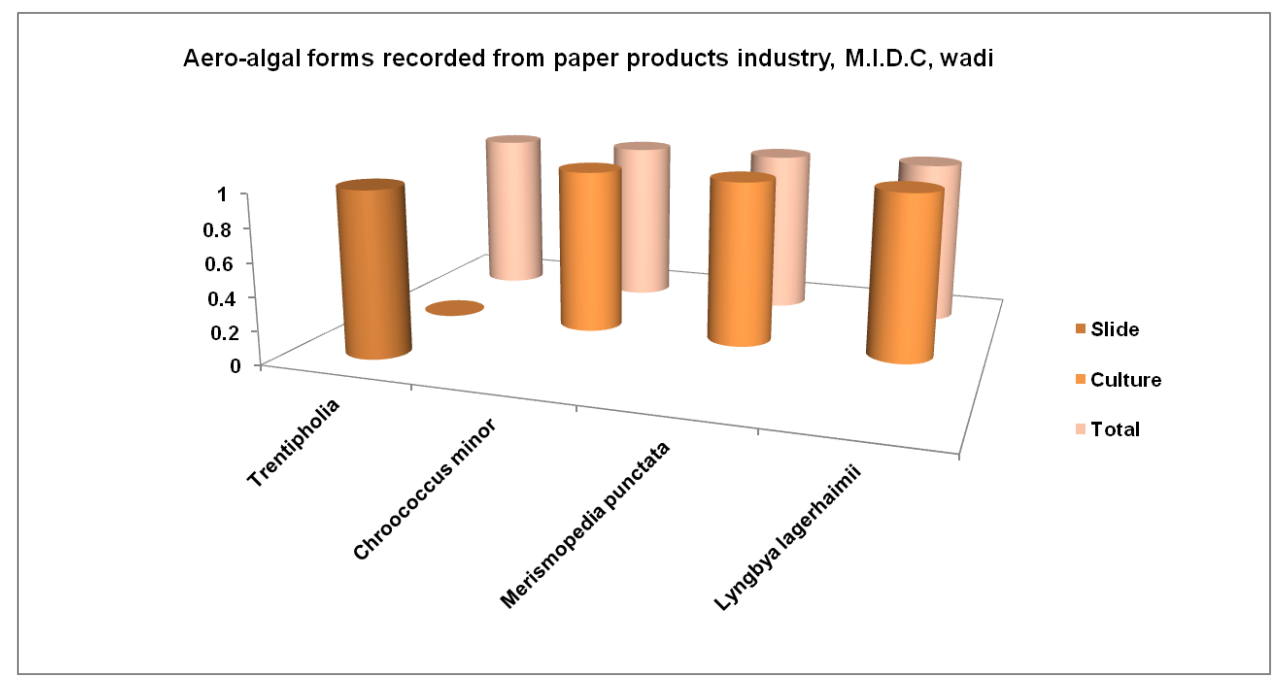



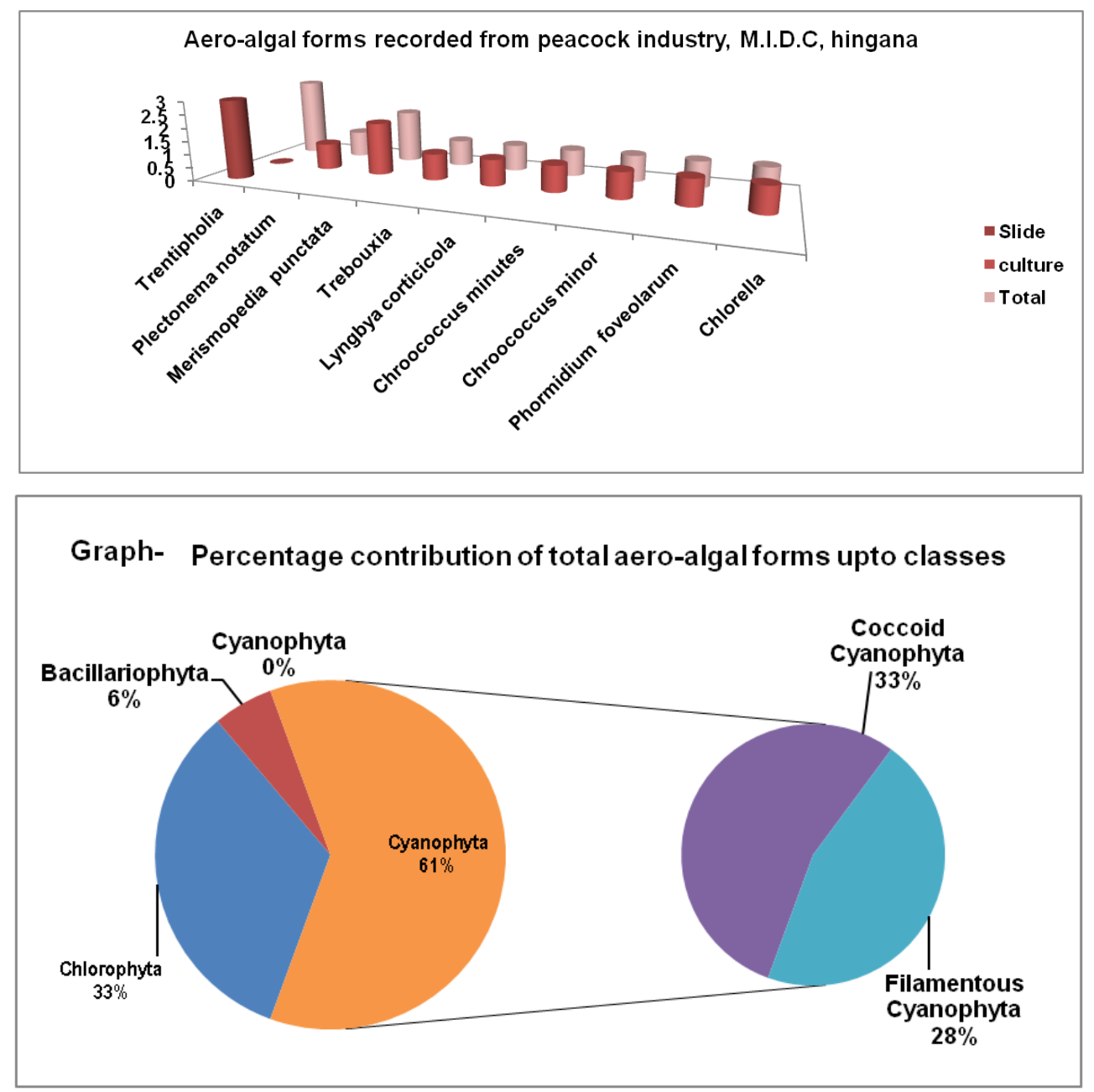

\section{RESULTS AND DISCUSSION}

Aero-algal sampling from cooling tower vicinity was done for the first time. All the three samples collected recorded positive for air borne algae (Observation Table-I and II). Cyanophyta was found to be dominant followed by chlorophyta and bacillariophyta respectively (Graph-II). Most of the aero-algal forms encountered have been reported earlier from Nagpur [30-33], Chalisgaon [21,22], Calcutta Metropolis [34,35], Jabalpur [36], Imphal, [23], Bareilly: [37], Pune: [26-28]. Some of them have also been reported from Cairo Districts of Egypt: [38], Mexico: [39, 40]. Some of the recorded forms like Phormidium, Lyngbya, Chlorella and Microcoleus reported to be allergenic has been encountered, [11,13, 20,40-43].

Total 18 aero-algal forms were recorded belonging to 9 genera out of which 10 were identified upto species level (observation table-I and II). Only one form, Trentipholia a member of chlorophyta group was reported from slide scanning. Remaining all the forms such as Plectonema, Merismopedia, Lyngbya, Chroococcus, Phormidium, Microcoleus, Trebouxia and Chlorella were recorded from culture only (Graph-I).

\section{CONCLUSION}

Presence of cooling tower results into manipulation of the climatic factors, such as temperature and humidity percentage. The high humidity percentage act as an unfavorable condition for the surviving of aero-algal forms results into sporulation, as also reported by Rosas et al. [39] on variation of airborne algae in Mexico and Evans [44] indicated the survival of certain algae due to modification of vegetative cells during unfavorable condition.

This spores required some incubation period under favorable condition to undergo for its vegetative development. This knowledge can be used as a possible solution for the allergenic patients. This can be achieved by manipulating the humidity percentage at both intramural as well as extramural sites. Manipulation of climatic factors can be done both at intramural as well as extramural sites by using water coolers, A. C, introducing water falls etc. It can be considered as possible manageable solution for patient suffering from allergy due to aerobiological pollutants. This is just a preliminary study with respect to the occurrence of aero-algal forms in two different industrials premises and the effect of cooling tower as a manipulating factor of temperature and humidity percentage on the distribution of aero-algal counts. A further study with respect to suggested possible manageable solution has to be done as a remedy for patients suffering from allergy due to presence of various aero-biological allergens.

\section{ACKNOWLEDGEMENT}

I would like to thank Dr. M. Z. Patel for his Moral and Financial support during this work. 


\section{REFERENCES}

1. Ehrenberg, G. C. Beitricht user die Zoo Bekanntmachung geeigenten Verhand lungo der Konig Press. Akad. Wiss Berlin.1844;9:194-197.

2. Salisbury, J. H. On the cause of intermittent and remittent fevers investigations, which tend to prove that these affections are caused by certain species of Palmellae. Am. J. Med. Sci.1866;51:51-57

3. Overeem, M. A. Van. On green organisms occurring in the lower troposphere. Rec. Trav. Bot. Neerl. 1937; 34:389-439

4. Schilichting, H. E. Jr. Viable species of algae and protozoa in the atmosphere. Lloydia. 1961;24:81-88

5. Schilichting, H. E. Jr. Meteorological Conditions affecting the dispersal of airborne algae and protozoa. Lloydia. 1964;27: 64-78

6. Schilichting, H. E. Jr. a. A preliminary study of algae and protozoa in sea foam. Bot. Marina. 1971;14:24-29

7. Schilichting, H. E. Jr. b. Evaluation of biological requirements in a atmospheric monitoring system: Algae and protozoa in the atmosphere U. S, T B P Aerobiology Handbook No. 1 Univ. Michigan Ann. Arbor. 1971:16-18

8. Schilichting, H. E. Jr. a. The survival of some fresh water algae under extreme environmental conditions. Trans. Amer. Microscop. Soc. 1974;93:610-613

9. Herold E. Schlichting. Some sub-aerial algae from Ireland, phycol. J. 1975;10:257-261

10. Talade, U. K. Airspora of Parbhani. Ind. Jour. Microbiol.1969;9:55-58.

11. Mittal A, Agarwal M. K, Goyal S. K and Shivpuri D. N. Preliminary studies on the allergenic algae of Delhi Metropolitan area, Botanical aspectis. Asp of Aller. and Appl. Immunol.1973;6:41-50

12. Mittal A, Agarwal M. K. and Shivpuri D. N. Studies on the prevalent algal forms of Delhi atmosphere. Asp of Aller. and Appl. Immunol.1974;7:52-62

13. Mittal A, Agarwal M. K., and Shivpuri D. N. Respiratory allergy to algae clinical aspects. Ann of Allergy. 1979;42:253-256

14. Ramalingam, A. Airspora of Mysore, Proc. Acad. Sci. Ind. 1971;74B: 227-240

15. Parswanath H. V. and A. Ramalingam. Seasonal varation in the air-born algae over a rural and an urban area. Current Science. 1979;48:956-957

16. Tilak. S. T. Aerobiology in Maharashtra. M. V. M. Patrika. 1974;9(1and2): 125-131

17. Tilak. S. T and Vishwe. D. B. Report on airborne algae from Aurangabad. Proc. $6^{\text {th }}$ Ind. Sci. Cong (1978); part-III: abstr. No. 25

18. Tilak S. T. Aerophycology-Aspects and Prospects. All India applied phycological congress Kanpur.1983:11-22

19. Tilak S. T. and Anis Sabia (1989). Algal aeroflora from Aurangabad. Ind. Jr. Aerobiol.1989;spl. vol: 65-68

20. Tilak. S. T. Aerophycology. Ind. Jr. Aerobiol.1992;spl. vol: 11-22

21. Ramchander Rao. K. S. Indoor and Outdoor Aeroalgae-Role as Allergens: Aerobiological Perspective, PanAmerican Aerobiology Association, Tulsa. 2005; Abstracts

22. Ramchandra Rao K. S. Algal Aerobiology in $19^{\text {th }}$ and $20^{\text {th }}$ Century, Approaches in Twenty First Century. $13^{\text {th }}$ National Conference on Aerobiology, Inst. Of. Sci., Nagpur.2005:68

23. Devi A. C. and N. I. Sing. Relevance of Meteorological parameters on the occurrence of BGA in the air-borne dust in Imphal area. $13^{\text {th }}$ National Conf. Aerobiology, Inst. of Sci., Nagpur. 2005:6

24. Sharma N. K., Surendra Sing and Ashwini Rai. Diversity and seasonal variation of viable algal particles in the atmosphere of sub-tropical city in India. Environmental Research.2006;102: 252-259

25. Jogita T. Pandkar and J. L. Tarar. Air borne algal pollutants from vegetable and a fish market at Nagpur, The Botanique. 2010;14 : 22-27

26. Jogita T. Pandkar. Presence of high algal diversity in pune air. Proceedings of International Conference on Biodiversity and its conservation. January 2011;PD7:1-10

27. Jogita T. Pandkar. Effect of humidity on the occurrence of aero-algal forms. The Botanique. 2013;17:112-115

28. Patil VS and Patil SR. Air Dispersion of Viable Algae in the extramural environment of Pune. International Journal of Advanced Research.2014;2:509-514

29. Perkins W. A (1957) The rotarod sampler. $2^{\text {nd }}$ semiannual Rep. Aerosol. Lab. Standford Uni, CLH.1957;186:1-66

30. Marathe Kusum and K. V. S. Reddy. Algal Aerospora of Nagpur, Advances in Pollen Spore Research. 1980:177183.

31. Kamat N. D. and P. S. Harankhedkar. Bark Algae of Nagpur, Maharashtra. Phykos. 1976;15(1and2):53-57

32. Kamat N. D. and M. Z. Patel. Soil algae of a rice field at different depths. The Botanique.1973;IV :101-104

33. Jogita T. Pandkar. Preliminary Study of Allergic Algae Of Air at Human Breathing Level From Nagpur. Biosciences, Biotechnology Research Asia. 2011;08 :159164

34. Santra S. C. Airborne Algae of Calcutta Metropolis,Phykos.1987:71-74

35. Chadha Asha and D. C. Pandey. Distribution of Algae on the walls of Buildings, Phykos. 1982;21:122-123

36. Karuna Verma. Air-Borne Algae, $8^{\text {th }}$ National conf. of air-born microbes, Y. M. College, Pune. 1996:16-18.

37. Nair, P. K. K, Sundarshan Kumar and B. N. Pande. Occurrence of algae in the aerial biomass at Bareilly and its bearing on human allergy. Curr. Sci. 1983:1199-1200

38. Ahmed D. El-Gamal. Aerophytic cyanophycean (cyanobacteria) from some Cairo Districts, Egypt. Pakistan Journal of Biological Sciences, 2008:11:12931302

39. Rosas I, Roy-Ocatla G, and Carrera J. Meteorological effects on variation of airborne algae in Mexico, Int. J. Biomet.1989;33:173-179

40. Bernstein, I. L. and Safferman, R. S. Viable algae in house dust. Nature.1970;227:851-852

41. Bernstein, I. L. and Safferman, R. S. Sensitivity of skin and bronchial mucosa to green algae. J Allergy.1966;28: 166-173

42. Paul Gorham. R and Carmichael, W. W. Phytotoxins from blue-green algae. Pure and Appl. Chem. 1979; 52:165-174

43. Goyal, S. K. Algae cause allergy. Science Reporter.1976;13:364-366

44. John H. Evans. The survival of freshwater Algae During Dry Periods. Jr. of Ecology.1959;47: 55-81 